\section{Splenic rupture as a complication of endoscopic esophageal bouginage}

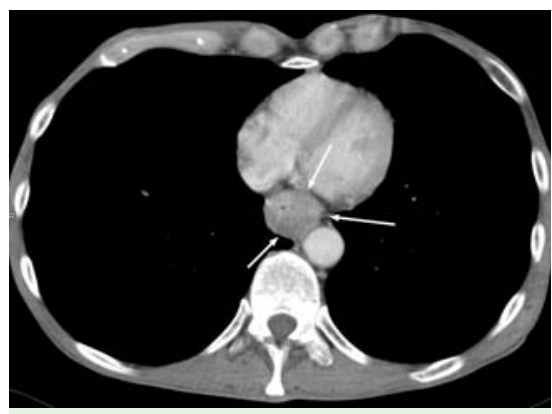

Fig. 1 Axial computed tomographic image of a squamous epithelial carcinoma stenosing the esophagus.

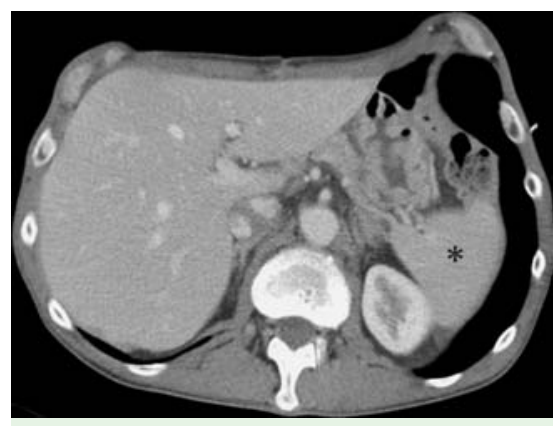

Fig. 2 Computed tomography (CT) showing an intact spleen (asterisk) before bouginage.

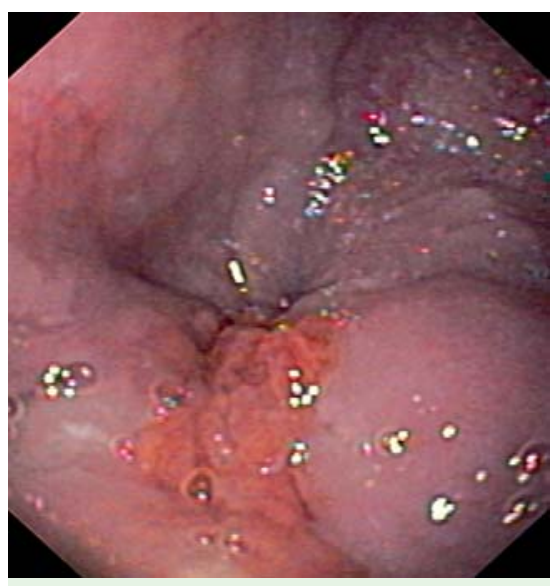

Fig. 3 Endoscopy with a GIF-160 endoscope (Olympus, external diameter $8.6 \mathrm{~mm}$ ) shows the stenosing carcinoma at a distance of $37 \mathrm{~cm}$ from the incisors.

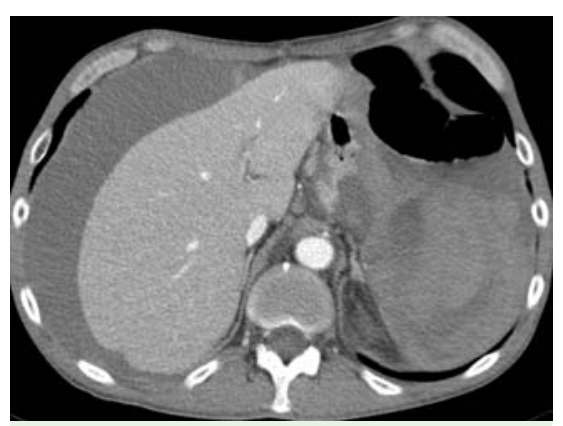

Fig. 4 Ruptured spleen with hemoperitoneum in $\mathrm{CT}$.

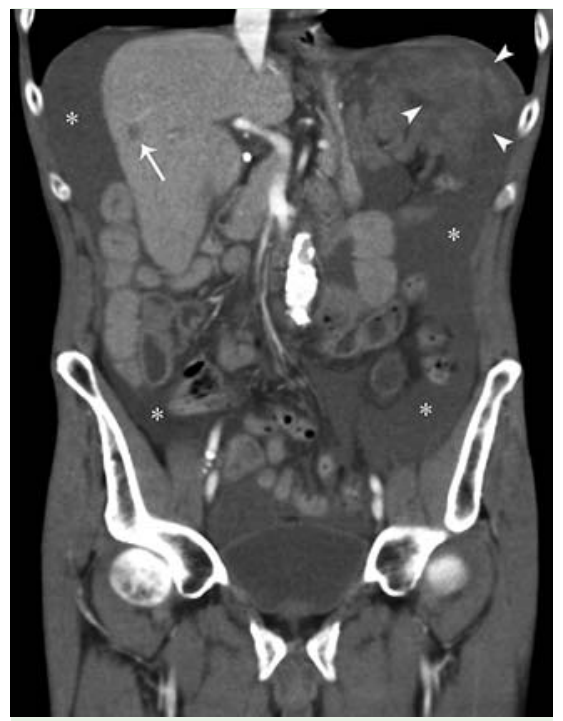
(arrow), ruptured spleen (arrowheads), and free intra-abdominal fluid (asterisks).

A 65-year-old patient presented with a 2month history of dysphagia and weight loss associated with a known squamous epithelial carcinoma of the esophagus. Computed tomography (CT) revealed the carcinoma of the distal esophagus $(\bullet$ Fig. 1) with a liver metastasis and an intact spleen ( $\bullet$ Fig. 2). Forty years ago a Billroth II gastroenterostomy had been performed because of duodenal ulcers.
Fig. 5 Coronal image with liver metastasis
Esophagogastroduodenoscopy

(EGD) showed a circular malignant esophageal stenosis ( $\bullet$ Fig. 3). After the second bouginage up to a diameter of $12 \mathrm{~mm}$ using Savary-Gilliard bougies the stenosis was passed. Four hours after this intervention the patient developed malaise symptoms combined with nausea that were initially interpreted as a reaction to the sedation and the bouginage.

The next morning the patient became pale, hypotonic, and tachycardiac, and complained about pain radiating from the back to the abdomen and, in particular, up to the left shoulder (Kehr's sign). The hemoglobin concentration had dropped. Immediate $\mathrm{CT}$ revealed a splenic rupture with an extended hemoperitoneum ( $\bullet$ Figs. 4 and 5). An emergency laparotomy was performed followed by surgical splenectomy. The postoperative course was uneventful.

Interventional EGD may cause complications such as bleeding, pain, infection, perforation, or, during sedation, cardiorespiratory problems. Some cases of splenic rupture occurring during endoscopic retrograde cholangiopancreatography $[1,2]$ or colonoscopy $[3,4]$ have been described in the medical literature. To date only a single case of splenic rupture after diagnostic EGD has been reported [5]. Rotating the endoscope within the duodenum, mechanical traction at the gastrosplenic ligament, and the formation of loops at the greater gastric curvature exerting a direct pressure onto the spleen are suspected as possible causes of splenic rupture [1].

Our patient suffered from a splenic rupture after EGD bouginage of a malignant esophageal stenosis with a history of Billroth II operation as a risk factor. This sort of complication may initially remain hidden behind unspecific symptoms, leading to a delay in diagnosis. In cases of postinterventional ailments and previous operations, splenic rupture should be taken into consideration as a rare differential diagnosis.

Endoscopy_UCTN_Code_CPL_1AH_2AF 
R. S. Goertz ${ }^{1}$, M. Raithel ${ }^{1}$, D. Strobel ${ }^{1}$, M. Wehler ${ }^{1}$, R. Janka ${ }^{2}$, A. Wein ${ }^{1}$, G. Maennlein' , E. G. Hahn' , F. Boxberger ${ }^{1}$

1 Department of Internal Medicine 1, Erlangen University, Erlangen, Germany

2 Institute of Radiology, Erlangen University, Erlangen, Germany

\section{References}

1 Deist TJ, Freytag A. Splenic rupture after ERCP. Z Gastroenterol 2003; 41: 579-582

2 Zyromski NJ, Camp CM. Splenic injury: a rare complication of endoscopic retrograde cholangiopancreatography. Am Surg 2004; 70 : $737-739$

3 Wherry DC, Zehner H jr. Colonoscopy-fiberoptic endoscopic approach to the colon and polypectomy. Med Ann Dist Columbia 1974; 43: $189-192$

4 Shah $P$. Splenic rupture as complication of colonoscopy. Indian J Gastroenterol 2007; 26: 150

5 Lewis FW, Moloo N, Stiegmann GV et al. Splenic injury complicating therapeutic upper gastrointestinal endoscopy and ERCP. Gastrointest Endosc 1991; 37: 632-633
Bibliography

DOI 10.1055/s-0029-1214497

Endoscopy 2009; 41: E228 -E229

(c) Georg Thieme Verlag KG Stuttgart · New York . ISSN 0013-726X

\section{Corresponding author}

\section{R. S. Goertz, MD}

Department of Internal Medicine 1 Erlangen University

Ulmenweg 18

91054 Erlangen

\section{Germany}

Fax: +49-9131-8535025

ruediger.goertz@uk-erlangen.de 